\title{
Teaching Writing In A Foreign Language To Law Students Using Authentic Internet Resources
}

\author{
Evgenia Dumina ${ }^{1 *}$, and Simon Suarez Cuadros ${ }^{2}$ \\ ${ }^{1}$ Moscow State Linguistic University, 38, Ostozhenka St, Moscow, 119034, Russian Federation \\ ${ }^{2}$ University of Granada, Avenida del Hospicio, S/N C.P. 18010, Granada, Spain
}

\begin{abstract}
The article is devoted to the development of foreign language writing skills of students of the direction of training "Jurisprudence" in the framework of professional education. The features of the process of teaching written business communication in a foreign language as an important component of the professional competence of a practicing lawyer are shown. The study suggests that with the help of authentic Internet resources, optimal conditions are created not only for acquaintance with written forms of communication adopted in the professional legal community: within the framework of the discipline "Foreign language in the field of professional communication" intercultural foreign language communicative competence of students is formed and improved.
\end{abstract}

\section{Introduction}

One of the main requirements for the foreign language training of modern law graduates is the formation and comprehensive development of all the competencies necessary for the successful integration of Russian young professionals into the world professional community and the implementation of international business cooperation in a global world. In this context, we cannot ignore another, in our opinion, significant factor - the demand for legal personnel in the modern labor market and the success of their professional activities largely depend on:

1) the level of readiness for business communication in a foreign language with different categories of citizens belonging to a different legal culture due to a different legal education, possessing different legal concepts, having a certain national mentality and language;

2) understanding the features of speech interaction and choosing behavioral strategies in each specific situation of foreign language communication;

3 ) the degree of being interested in the result of interpersonal communication in various spheres of life: social, professional, scientific.

It's noteworthy that the widespread use of modern technical means of communication, such as mobile phones, e-mail, and the Internet, has not only significantly changed the ways to access and transmit a wide range of information, but also opened up other opportunities for sharing experience and relevant knowledge within the professional legal community. Thus, the informatization of the society has led to the creation of a single information and communication space, unlimited access to information resources, and the increase in the volume of data created. As a result, new areas of professional activity have emerged and business and intercultural contacts in the legal environment have expanded. At the same time, the transition to the exchange of legal documents in an electronic form in various formats has contributed to the fact that written communication in a foreign language has become more acute, and it is deemed as an important component of the work of a new generation of lawyers. The ability to correctly, logically and accurately record and transmit professionally relevant information, to express

\footnotetext{
*Corresponding author: dumina@list.ru
} 
thoughts and opinions in writing, as well as to compose and interpret legal texts, mainly legal documents, in a foreign language, is highly valued in the modern world and plays an important role in ensuring the performance of professional duties of a modern lawyer.

According to N. V. Abramova, a graduate of a law school can be considered prepared for independent speech activity judging by "not only the presence of legal knowledge, skills, acquired legal traditions and behavioral stereotypes, but also a formed culture of foreignlanguage business communication" [1, p.89]. This means that fluency in a foreign language in the field of law in general and skills of foreign language productive writing in particular should be considered as attribute qualities of a lawyer-practitioner, reflecting the level of his speech culture and communicative literacy as well as serving as a manifestation of his competence and professionalism.

Emphasizing the practical importance of developing communication skills in law students, we believe that the formation and improvement of writing skills require constant attention in the process of teaching the language of the specialty. This, in turn, dictates the urgent need to find new approaches to professional training of legal personnel and raises the question of modernizing information technology support for higher linguistic education.

\section{Authentic Materials as an Important Methodological Condition for the Formation of Foreign Language Writing Skills}

There is no doubt that the introduction of authentic Internet resources in the educational process makes it possible to move to a qualitatively new level in teaching foreign language professional communication and becomes an effective means of developing skills and abilities of crosscultural written communication among law students.

Integration of authentic Internet resources in the process of teaching foreign languages helps students to immerse themselves in a special information-linguistic and professional environment, which, of course, leads to strengthening the practical orientation of foreign language training of future lawyers, increasing their cognitive activity and interest in the specialty language. When teaching intercultural communication, we turn to authentic materials created by native speakers and projected onto native speakers of the language studied, thereby "creating the illusion of participation in the daily life of the country" [4, p. 117].

Due to their linguistic and extralinguistic features, authentic Internet resources compensate for the lack of a natural language environment, starting from the early stages of learning writing, since we use country-specific and legal texts mainly in an unadapted form as a didactic tool. Many authors consider it quite justified to use authentic texts for classroom and extracurricular work at all stages of learning a foreign language in a non-linguistic University. Taking this aspect into account, the task of the teacher is to organize the material that was not originally intended for educational purposes and was taken from the original Internet sources, and through methodical processing transform it into an educational tool fully preserving all the parameters of genre and stylistic authenticity of the language (plain and legal), the reliability of socio - cultural information, the author's personality, presentation of texts in their original form [3]. In our opinion, while didactizing these tools, it is permissible to make only minor methodological changes, and only if the "live" speech material represents legal, linguistic, cultural, historical or educational values that will help to successfully form and develop a lawyer's professional personality. Otherwise, it is better to completely exclude the material that is too difficult to learn, since negative aspects associated with language and / or content difficulties lead to lags and failures in the subject and reduce motivation for in-depth study of the professional language.

Due to the variety of sources of information (video, audio, print, electronic materials, real-world objects, etc.), the greatest difficulty lies in the selection of foreign-language Internet 
resources, since authentic materials must correspond to the level of foreign language proficiency of students, their individual capabilities and social needs, and therefore contain professionally significant, relevant and reliable information in this subject area [2]. It may seem that having constant and unlimited access to any information on the Internet, the teacher will easily be able to find suitable material, which in terms of content and level of language complexity may be advisable to use at each specific stage of learning writing. However, the main problem for the organizer of the educational process is not to systematize a large flow of information, but to objectively determine the didactic value and reliability of the material offered by foreign resources. Due to the lack of clear guidelines and accurate understanding of the possibilities of using authentic Internet resources for educational purposes, in fact, all responsibility for the relevance, quality and methodology of their use in practical foreign language classes rests with the teacher. Before integrating information technologies into the process of teaching foreign languages, it seems to be necessary to outline the full range of possible problems associated with the active use of authentic Internet resources [7]. Therefore, we may assert that you shall start with a thorough examination of existing foreign language resources, namely, in terms of credibility of the origin source, and also with the study of ideological positions and ideological orientations of authors and publishers on the Internet.

Next, you need to deeply and critically analyze the selected authentic online resources, paying attention primarily to the communicative specificity of the legal profession, in particular, to the importance of skills and the productive skills of writing in a foreign language as a means of intercultural business communication of specialists in this sphere. Basing on the data obtained, the teacher develops a strategy for the formation of professional written communicative competence among students with multi-level language training, since authentic materials allow to individualize the learning process and to create the most favorable conditions for self-education, self-control and self-assessment [6].

Summarizing the above, we can conclude that it is possible to achieve consistently high results in mastering the discipline "Foreign language in the field of professional communication" only if each student is given the opportunity to choose from among the authentic Internet resources recommended by the teacher depending on:

1) the way information is perceived (auditory / auditory or visual / visual);

2) the form of providing information (text, audio, graphic, numeric information, video

files);

3) problem tasks aimed at developing and improving foreign language writing skills, taking into account individual abilities and personal interest.

As an example of an authentic Internet resource may serve http: www.juris.de. It is a legal website that contains a selection of normative documents on all branches of German law, lists of links to other official legal resources, blocks of legal news items, expert opinions and analytical materials on topical issues of law and law enforcement. Legal webinars regularly held on the De jure portal can also be of great interest and significance for students studying German and German law. Since the speakers of an online seminar are usually leading experts in the field of law, an individual student or a group of students have the opportunity to watch, listen to and learn from legal scholars or practitioners with extensive experience in court proceedings, and then give a written legal assessment of the situation, expressing their own reasoned opinion on the formulated problem.

\section{Conclusion}

Thus, depending on the level of formation of foreign language communicative competence, the level of theoretical and practical professional training and the General cultural level of students, the teacher develops a set of tasks for the development and improvement of skills and abilities necessary for creating statements and implementing speech intentions in written legal discourse 
in a foreign language. We share the point of view presented by P. V. Sysoev and V. V. Zavyalova that "mastering the material through practical activities for the interpretation and creation of a foreign language written legal discourse by students will allow them to quickly and better master the necessary competencies" [5, p. 321].

In conclusion we shall say that in order to develop information and analytical skills for reproducing and creating various types of written texts on professional topics based on the original language material it is necessary to note the importance of systematic work with authentic Internet resources in the process of teaching a foreign language to students of nonlinguistic specialties. Our experience at the faculty of international law and justice of Moscow State Linguistic University fully confirms the conclusions made.

\section{Acknowledgments}

This work was supported by the Russian Foundation for Basic Research, grant No.20-01200466

This paper was financially supported by the Russian Foundation for Basic Research, grant No. 20-012-22046.

\section{References}

1. N. V. Abramova. Preparation of future lawyers for business foreign language communication in the theory and practice of higher education, News. Saratov national research state University named after N. G. Chernyshevsky. Nov. series. 2013. Vol. 13. Ser. Philosophy. Psychology. Pedagogy, issue 1, pp. 88-91 (2013)

2. D. K. Bartosh, N. D. Galskova, A. V. Koptelova, M. V. Kharlamova, Technology of elearning in foreign languages: state and prospects [Text]: monograph, M : MSPU. 262 p. (2018)

3. Yu. A. Vorobyov, Use of authentic texts of professional orientation in the process of formation of linguistic and cultural competence among students of non-linguistic universities. Azimuth of scientific research: pedagogy and psychology. Association of professional analysts of autopoiesis systems. Tolyatti. Vol. 8. No: 3 (28). pp. 72-74 (2019)

4. N. A. Savinova, L. V. Mikhaleva, Authentic materials as an integral part of the formation of communicative competence. Bulletin of Tomsk state University. No. 294. pp. 116-119 (2007)

5. P. V. Sysoev, V. V. Zavyalov, Teaching foreign language written legal discourse to students of the "Jurisprudence" training direction. No: 41. pp. 308-326 (2018)

6. S. S. Khromov, N. A. Kameneva, Methods of using authentic Internet resources for teaching English. Modern research of social problems. No: 7. pp. 275-284 (2015)

7. R. H. Azri, M. H. Al-Rashdi, The effect of using authentic materials in teaching. International journal of scientific \& technology research. Vol. 3, issue 10. Available at: https://www.ijstr.org/final-print/oct2014/The-Effect-Of-Using-Authentic-Materials-In-

Teaching.pdf (accessed 25 September 2020) 